\title{
Hip-spine syndrome: the problem from the biomechanical point of view
}

\author{
A.O. Kotelnikov, S.O. Ryabykh, A.V. Burtsev
}

Russian Ilizarov Scientific Center for Restorative Traumatology and Orthopaedics, Kurgan, Russian Federation

\begin{abstract}
Relevance Compensatory mechanisms of the lumbar spine-pelvis complex in concurrent degenerative changes remain a poorly understood problem. Numerous publications report data either from the point of view of spinal pathology or from the point of hip joint damage. Objective To evaluate changes in the parameters of the spine-pelvis sagittal balance in patients with the hip-spine syndrome. Materials and methods Two groups of patients with hip-spine syndrome were analysed: 1 ) "Hipspine" group $(\mathrm{n}=54)$ and 2$)$ "Spine-hip" group $(\mathrm{n}=66)$. All patients underwent radiographic examination. Radiographs of the spine with the capture of the head and hip joints in the anteroposterior and lateral projections in the standing position were taken. Results In the first group, the position of the pelvis was within normal anteversion or pelvic hyperanteversion. In the second group, pelvic retroversion was revealed; normal position of the pelvis (without its compensatory deviation) was present only in several cases. Discussion Regularities in the compensatory mechanisms in the hip-spine syndrome variants have been identified. However, cases with pelvic retroversion require further study and assessment of the balance after surgery. Conclusion Compensatory mechanisms in hip-spine syndrome depend on the dominance of the pathological process (joints or spine), which must be considered in evaluation of the parameters of the sagittal balance in these patients. Keywords: hip-spine syndrome, sagittal balance of the trunk, sagittal pelvic parameters, degenerative diseases of the spine, degenerative coxarthrosis
\end{abstract}

\section{RELEVANCE}

High incidence of concurrent pathology of the spine and hip joint that ranges from 28.5 to $70 \%$ [14] as well as a significant number of patients suffering from pain after surgical treatment in the lumbosacral spine (14-50 \%) and / or after hip arthroplasty (17$20 \%)[2,5,6]$ led to the formation of a separate nosological group, hip-spine syndrome. At present, it has been proven that the sagittal profile of the trunk strictly correlates with the quality of life [7-10], and the complex "hip joints and lumbosacral spine" (hereinafter the HJ-LSS complex) plays a key role in the compensatory mechanisms for trunk imbalance [10-14].

The main issue in the investigation of the hipspine syndrome is the biomechanical spine-to-pelvis imbalance in the sagittal plane [3, 15-20]. A number of publications describe the "stair-like" mechanism in the development of degenerative pathology from a static deformity, then the tilt of the pelvis in the sagittal plane and, less frequently, in the frontal plane, anteversion/retroversion of the pelvis with hyperlordosis/hypolordosis in the lumbar spine [1719, 21-23]. It induces or exacerbates degenerative changes in the HJ-LSS complex at the "upper floor" (LSS) or "lower floor" (HJ) level.

The key hypothesis, from our point of view, is the evaluation of the parameters of the spine-pelvis sagittal profile, which can help the surgeon determine the root cause of hip-spine syndrome development in a patient, i.e. the leading pathology, the hip joints ("Hip-spine") or the spine ("Spine-hip").

Our purpose was to evaluate the parameters of the spine-to-pelvis sagittal profile in patients with the hip-spine syndrome.

\section{MATERIAL AND METHODS}

The study was conducted at the 1) department of arthroplasty and 2) adult neurovertebrology department of the clinic for spine pathology and rare diseases of the RISC for RTO of the ministry of health of the Russian Federation.

Study design Prospective controlled cohort study at one centre.
Evidence level IV (UK Oxford, version 2009).

Sample features: It was assumed that the primary cause of the hip-spine syndrome condition was according to the nosology profile of the department the patients were referred to.

Two groups of patients with clinical manifestations of the hip-spine syndrome were analised: 1) Hip-spine 
group ( $\mathrm{n}=54)$ and 2) Spine-hip group $(\mathrm{n}=66)$. According to the Offierski\&MacNab's classification, patients with a simple (dysfunction cause easily revealed) and complex (dysfunction cause difficult to reveal) type of the hip-spine syndrome were identified. In group 1, there were 22 (40.7 \%) males and 32 (59.3\%) females. In group 2, gender subgroups were similar, 17 (25.7\%) males and 49 (74.3\%) females. Mean age in group 1 was $61.3 \pm 9.9$ (range, $40-80$ years), and $64.8 \pm 7.5$ (range, $42-83$ years) in group 2. Recruitment period was 2016-2018.

Inclusion criteria were:

- Degenerative pathology in the HJ-LSS complex associated with pain both in the hip joint areas and in the lumbosacral spine area;

- A complete radiographic file;

- No history of previous interventions in the anatomic complex.

Calculation of the sagittal and frontal balance parameters was performed using the Surgimap software program. The evaluation criteria were nine parameters of the sagittal trunk balance (CL, TK, TLK, LL, PI, PT, SS, PI - LL, SVA). According to anteroposterior radiographs, the angle of pelvic tilt, scoliotic deformity of the lumbosacral spine according to the Cobb method, and the angle of the sacrum slope were evaluated. Degenerative changes in the hip joint were assessed in the AP radiograph of the pelvis according to the Kosinskaya classification.
Degeneration of the lumbosacral spine was studied in the AP and lateral radiographs (patients of Hip-Spine group) and using CT, MRI and functional radiographs of the lumbosacral spine (patients of Spine-hip group). LSS radiographic study evaluated four parameters of spinal degeneration: arthritis of the facet joints, osteophytes of vertebral bodies, intervertebral disk height and foramen height. The main parameters of the sagittal spine-pelvis relationship were compared between healthy subjects and patients with the hip-spine syndrome.

Clinical examination was conducted according to the protocol and such questionnaires and systems as VAS LBP VAS LE, Harris Hip score, ODI and the Charlson comorbidity index. Everyday functional activity was studied with IPAQ.

Statistical processing was performed using the Statistical Package for the Social Sciences (SPSS), version 22.0 (SPSS Inc., Chicago, IL, USA). Normality of the distribution of the parameters studied was carried out using the method of descriptive statistics (a histogram with a normal distribution curve). For intergroup comparative assessment of differences in the average values of the analyzed parameters, the nonparametric $\mathrm{H}$-Kruskal-Wallis test was used. In the cohort assessment of the impact of the parameters PI - LL and SVA on the value of VAS LBP and VAS LE, one-way analysis of variance (ANOVA) was used for the groups. Statistical differences were regarded as significant with bilateral $\mathrm{p}<0.05$. The results are presented as $\mathrm{M} \pm \mathrm{m}$.

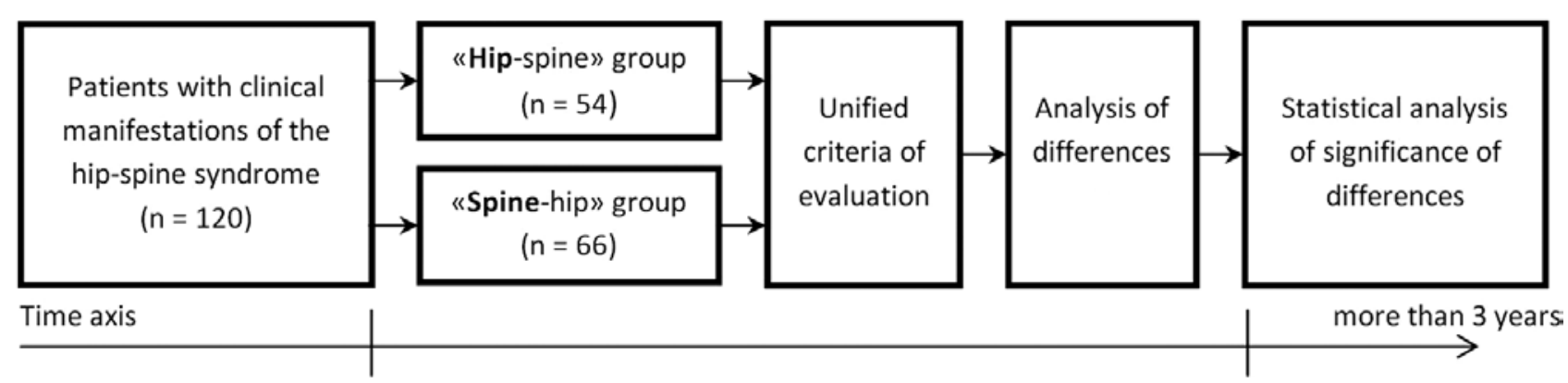

Fig. 1 Strategy of group recruitment

\section{RESULTS}

In the first group of patients, local pain prevailed in the hip joint: VAS $6.2 \pm 3.1$ (range, 3 to 10 ) and in LSS: VAS $4.9 \pm 2.5$ (range, 2 to 8 ). There were no other signs of neurological deficit. The average Charlson comorbidity index was $65.7 \pm 31.7$ (range, 0 to 100$)$, the quality of life on the Harris hip scale was $44.8 \pm 14.3$ (range, 39.4 to 58.6), and the ODI was $40.6 \pm 15.9$ (range, 37 to 72 ), which indicate a pronounced deterioration in the quality of life of the patients. According to the classification of Offierski and MacNab, patients with a simple "hip-spine" syndrome prevailed (the source of dysfunction is 
the hip joint, $\mathrm{n}=42$ or $77.7 \%$ ); 12 cases were with complex syndrome (22.3\%).

The radiographic study revealed uni- or bilateral coxarthrosis of grade 3 in 54 patients. All had LSS degeneration signs such as vertebral body osteophytes in $52(96.29 \%)$ patients, a decrease in the height of the intervertebral discs and foramens in 43 (79.62 \%) patients, arthrosis of the facet joints in 48 (88.88\%), and mainly the lower lumbar segments were affected.

The sagittal balance parameters are presented in Table 1. An increase in C7-S1 SVA over $40 \mathrm{~mm}$ (average, $+38.7 \pm 39.7 \mathrm{~mm}$; $\min .-25 \mathrm{~mm}$, max. $145 \mathrm{~mm}$ ) was observed in 29 (53.7 \%) patients. In general, an increase in lumbar lordosis and a decrease in thoracic kyphosis were noted in this group in comparison with the parameters of healthy people. The parameters of the pelvis were of particular interest: 27 patients (50.0\%) had pelvic hyperanteversion with hyperlordosis of the lumbar spine (Fig. 1), 25 (46.3 \%) subjects had pelvis position corresponding to the parameters of healthy people, and compensatory pelvic retroversion with hypolordosis of the lumbar spine was revealed in 2 patients ( $3.7 \%$ ). The frontal radiographic parameters of the first group patients, presented in Table 2, showed changes in 12 patients (22.2 \%) due to scoliotic deformity in the lumbar spine.

Neurological status of various combinations in the second group was neurogenic intermittent claudication $(\mathrm{n}=41,62.1 \%)$, radiculopathy $(\mathrm{n}=33,50.0 \%)$, lower mild paraparesis $(\mathrm{n}=4.1,6.1 \%)$, vertebrogenic pain $(\mathrm{n}=66,100 \%)$; VAS $6.7 \pm 2.4$ (range, 5 to 9); arthrogenic pain ( $\mathrm{n}=66,100 \%)$; VAS $4.6 \pm 2.5$ (range, 4 to 9). The causes of the leading degenerative spinal component were degenerative instability $(\mathrm{n}=22,33.3 \%)$, degenerative scoliosis $(\mathrm{n}=14$, $21.2 \%)$, degenerative stenosis $(\mathrm{n}=30,45.5 \%)$. The Charlson comorbidity index was $51.7 \pm 31.6$ (range, 2 to 97). The quality of life according to ODI was $46.6 \pm 19.8$ (range, 41 to 75 ), Harris hip score $72.8 \pm 13.3$ (range, 57 to 86 ) that indicated a poor quality of life. According to the classification of Offierski and MacNab, as in the first group, patients with a simple hip-spine syndrome prevailed (source of dysfunction was the lumbosacral spine, $\mathrm{n}=54$, $81.8 \%$ ); 12 cases had a complex syndrome (18. $2 \%$ )

Radiographic study revealed different grades of coxarthrosis: grade 1 in three patients (4.5\%); grade 2 in 55 (83.3\%); grade 3 in 8 (12.2\%). Due to the different severity and combination of degenerative changes in the lumbar spine, group 2 was divided into several nosological subgroups: a) degenerative stenosis of the spinal canal type C, D according to Schizas was 32 (48.4\%) cases; b) degenerative instability of more than 5 White and Panjabi points in $11(16.6 \%)$ cases; c) instability + stenosis of the spinal canal in 9 (13.6\%); d) degenerative scoliosis + stenosis of the spinal canal in $9(13.6 \%)$; e) degenerative scoliosis + instability + stenosis of the spinal canal in 5 (7.8\%) cases.

Parameters of the sagittal balance are presented in Table 1. Disorder of the entire sagittal trunk balance was revealed in 29 patients (43.9\%), an increase in C7 - S1 SVA of more than $40 \mathrm{~mm}$. In contrast to the first group, the number of patients with pelvic retroversion and hypolordosis of the lumbar spine prevailed, $\mathrm{n}=59$ (89.4 \%) (Fig. 2), and pelvic sagittal alignment corresponded to normal parameters of healthy people in only 7 patients (10.6\%). Significant frontal deviations were revealed in 31 patients $(46.9 \%)$ of the second group, presented in Table 2, and were due to scoliotic deformity of the lumbar spine.

The average daily functional activity among the patients of the two groups according to the IPAQ questionnaire was $5.6 \pm 1.3$ points and shows a low functional activity of the patients and their predominantly sedentary lifestyle.

The distribution of sagittal spine-pelvis parameters in two groups is presented in Figure 3. The distribution for all parameters was not normal; therefore non-parametric criteria of the analysis of variance and correlation were used. The results of the correlation analysis show a strong relationship between LL and SS ( $r=0.84 ; p<0.05)$, which indicates the relationship between pelvic anteversion/ retroversion and hyper/hypolordization of the lumbar spine. A positive correlation was also observed in the "Spine-Hip" group between the VAS LBP value and the "PI - LL" and "SVA" values $(r=0.62$; $\mathrm{p}<0.05)$. Significance of differences in the sagittal parameters between the two groups, according to the Kruskal-Wallis $\mathrm{H}$ test is presented in Table 3. A weak significance of differences was noted between all parameters analysed, except for SS $(p=0.05)$. 
Benij Ortopedii, Vol. 25, no 4, 2019

Table 1

Sagittal spine-pelvis parameters in healthy subjects and patients with the hip-spine

\begin{tabular}{|c|c|c|c|}
\hline Parameter & Healthy subjects & Hip-spine group & Spine-hip group \\
\hline \multicolumn{4}{|c|}{ PI (pelvic incidence) } \\
\hline Minimum & 33 & 32 & 27 \\
\hline Maximum & 85 & 75 & 81 \\
\hline Medium & $51.7 \pm 11.5$ & $53.4 \pm 10.4$ & $50.1 \pm 12.1$ \\
\hline \multicolumn{4}{|c|}{ PT (pelvic tilt) } \\
\hline Minimum & -1 & -5 & 7 \\
\hline Maximum & 27.90 & 28 & 39 \\
\hline Medium & $12.3 \pm 5.9$ & $+11.5 \pm 6.3$ & $23.3 \pm 6.7$ \\
\hline \multicolumn{4}{|c|}{ SS (sacral slope) } \\
\hline Minimum & 19.5 & 18 & 3 \\
\hline Maximum & 65.5 & 59 & 50 \\
\hline Medium & $39.4 \pm 9.3$ & $41.7 \pm 9.1$ & $26.2 \pm 9.3$ \\
\hline \multicolumn{4}{|c|}{ Lumbar lordosis (LL) } \\
\hline Minimum & -26 & -30 & +2 \\
\hline Maximum & -76 & -87 & -82 \\
\hline Medium & $-46.5 \pm 11.1$ & $-57.3 \pm 11.2$ & $-38.5 \pm 15.9$ \\
\hline \multicolumn{4}{|c|}{ Thoracic kyphosis (TK) } \\
\hline Minimum & +25 & +10 & +1 \\
\hline Maximum & +72 & +65 & +66 \\
\hline Medium & $+47 \pm 9.2$ & $+31.7 \pm 11.2$ & $+28.2 \pm 14.3$ \\
\hline \multicolumn{4}{|c|}{ Sagittal vertical axis (SVA) } \\
\hline Minimum & +8 & -25 & -28 \\
\hline Maximum & +77 & +145 & +159 \\
\hline Medium & $+36 \pm 15$ & $+38.7 \pm 39.7$ & $+40.3 \pm 41.6$ \\
\hline
\end{tabular}

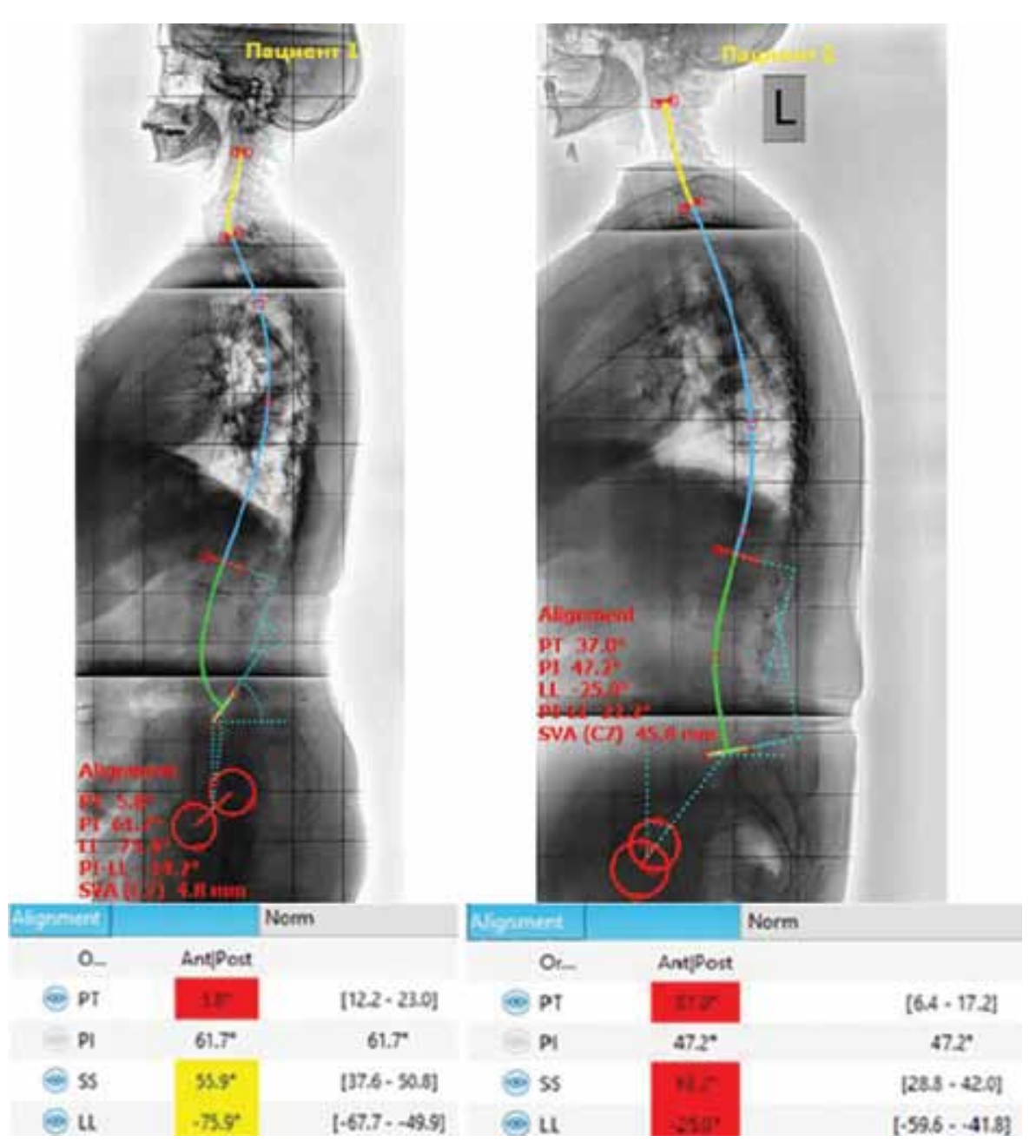

Fig. 2 Variants of compensatory mechanisms in patients of the "Hip-spine" and "Spinehip" groups: patient 1 from the "Hip-spine" group with pelvic hyperanteversion and hyperlordosis of the lumbar spine; patient 2 from the "Spine-hip" group with pelvic retroversion and hypolordosis of the lumbar spine 
Genij Ortopedii, Vol. 25, no 4, 2019

Table 2

Frontal pelvis-spine parameters in patients with hip-spine syndrome

\begin{tabular}{|l|c|c|}
\hline Parameter & Hip-spine group & Spine-hip group \\
\hline Pelvic tilt & 0 & 0 \\
\hline Minimum & 14 & 5 \\
\hline Maximum & $2.1 \pm 2.5$ & $1.9 \pm 1.5$ \\
\hline Medium & 0 & 0 \\
\hline Sacral slope & 0 & 3 \\
\hline Minimum & 0 & $0.1 \pm 0.4$ \\
\hline Maximum & \multicolumn{2}{|c|}{} \\
\hline Medium & 0 & 0 \\
\hline Scoliotic deformity in the lumbosacral spine & 38 & 40 \\
\hline Minimum & $3.3 \pm 6.7$ & $5.9 \pm 8.8$ \\
\hline Maximum & \multicolumn{2}{|c|}{} \\
\hline Medium &
\end{tabular}

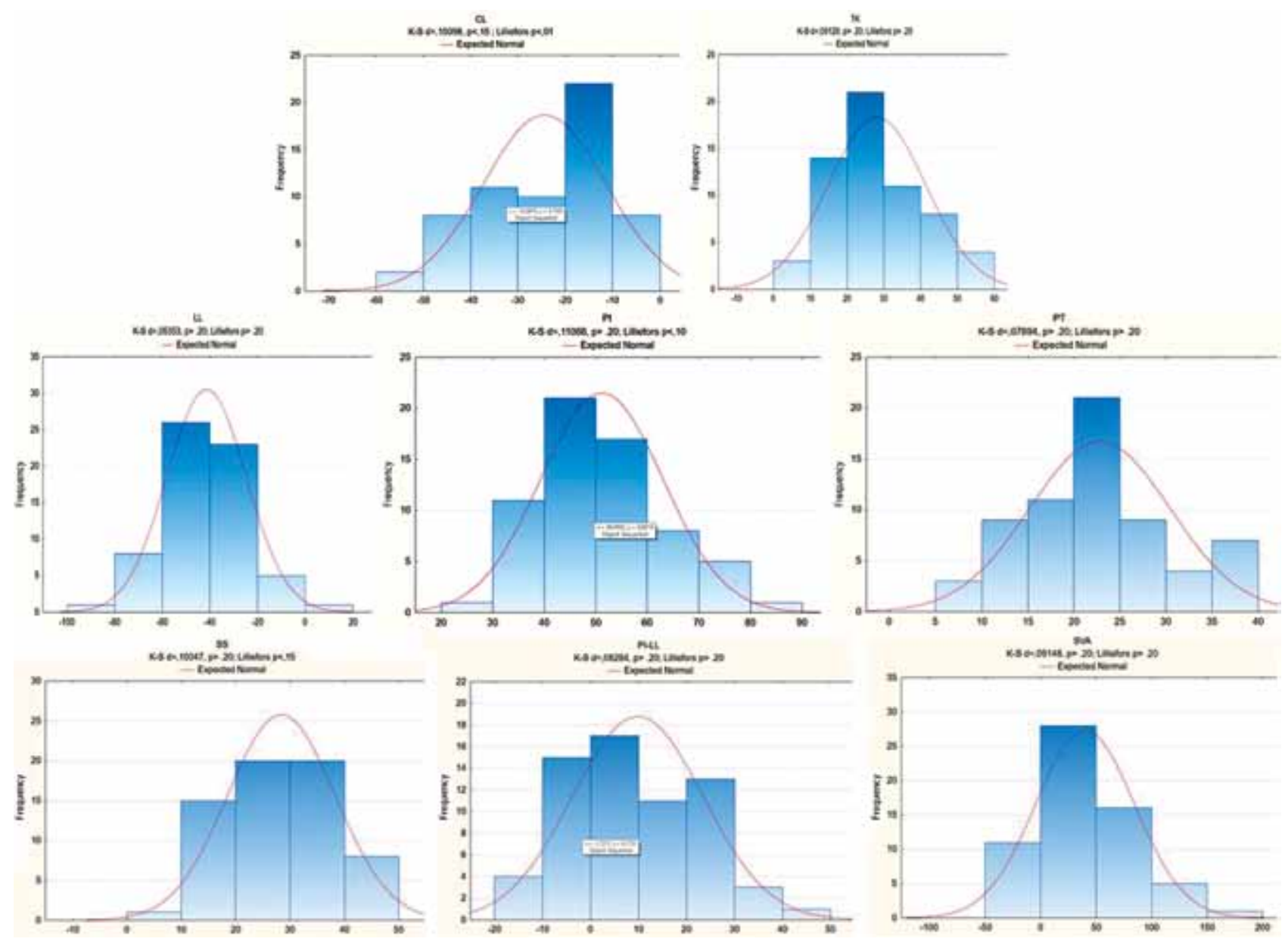

Fig. 3 Distribution of spine-pelvis parameters in two groups

Table 3

\begin{tabular}{|l|c|}
\hline \multicolumn{1}{|c|}{ Parameter } & $\begin{array}{c}\text { Significance of difference in sagittal parameters between «Spine-hip» group and } \\
\text { Hip-spine group according to H Kruscal Wallis test }\end{array}$ \\
\hline Lumbar lordosis (LL) & $\mathrm{p}=0.08$ \\
\hline PT & $\mathrm{p}=0.07$ \\
\hline SS & $\mathrm{p}=0.05$ \\
\hline PI-LL & $\mathrm{p}=0.09$ \\
\hline Sagittal vertical axis (SVA) & $\mathrm{p}=0.08$ \\
\hline Thoracic kyphosis (TK) & $\mathrm{p}=0.08$ \\
\hline Cervical lordosis (CL) & $\mathrm{p}=0.09$ \\
\hline
\end{tabular}




\section{DISCUSSION}

Hip-spine syndrome as a complex of symptoms in combined degenerative lesions of the hip joints, sacroiliac joint, and lumbar spine was first introduced by Offierski, MacNab in 1983 [24]. Some researchers opine that the primary cause of the hip-spine syndrome is degenerative changes in the hip joints, but a number of others point to the role of spinal pathology [5, 2532]. Based on the clinical examination, it is difficult to distinguish hip pathology from degenerative spine pathology. Moreover, those pathologies are frequently concurrent and interrelated, and to determine the main source of pain is not easy. Symptoms like pain in the lumbosacral, gluteal region, irradiation / no irradiation to the lower extremities, lameness / without claudication are typical for patients with degenerative changes in the spine and hip joints [5, 33-35]. By assessing the Rg-disorders in the spine and hip joints, significant changes in these parts of the body are found in the overwhelming number of cases. The inability to reliably determine the root cause of pain leads to an irrational approach to treatment and, consequently, an increase in the time and cost of treatment, affects the relationship between the patient and the doctor, and also increases the risk of legal problems [1, 4, 36, 37].

In the surgical correction of spinal deformities, it is the effect on the sagittal balance and lumbar-pelvic parameters that significantly improves the quality of life according to HRQoL scores [38-44]. The pioneer in the study of sagittal balance is Jean Dubousset, who showed the need to understand the balance assessment in his numerous works [8, 45-47]. Parameters of the sagittal spinal-pelvic balance of the vertical posture were studied by G. Duval-Beapure et al. in 1992 [48] with barycentrimetric studies. A large number of radiological parameters were adopted for an integral assessment of the balance. Position of the pelvis is a key in determining the sagittal balance of the spine. It should be remembered that most of the compensatory abilities in imbalance are possible due to a change in the position of the pelvis $[14,22,49-53]$. The main parameter of the pelvis is PI (deviation of the pelvis from the vertical axis), due to the fact that it is an unchangeable morphological and individual parameter for each person. Due to PI integration with dynamic parameters of the pelvis and spine (PT is the horizontal inclination of the pelvis,
SS is the inclination of the sacrum, LL is the lumbar lordosis), we can detect one or another local sagittal imbalance of the trunk, comparing the data obtained from healthy people of different age groups.

Dynamic parameters are interrelated, with the strongest correlation among healthy people being traced between lumbar lordosis GLL and the sacrum slope SS $(\mathrm{p}<0.001 ; \mathrm{R}=0.86)[14,17,54,55]$. The ideal value of RT (pelvic tilt) does not exceed $50 \%$ of the PI parameter, and the ideal value of the sacrum slope SS exceeds $50 \%$ of PI [55-58]. Recent works on the study of the sagittal profile in patients with hip-spine syndrome show various variants of static deformities in such patients. Foreign and domestic authors divided patients of this category into two groups: patients with excessive pelvic anteversion and lumbar hyperlordosis, and patients with pelvic retroversion and lumbar hypolordosis $[17,19,21$, $22,53,54]$. The data of our study coincide with the findings of previous studies, and also indicate the relationship of the compensatory mechanism of the sagittal imbalance with the prevailing pathology, "spine" or "hip" in the HJ-LSS complex. So, our study revealed that patients in whom pain in the hip joints prevailed (Hip-Spine group, $n=54$ ), had the position of the pelvis within the normal anteversion or there was pelvic hyperanterversion.

Two cases with pelvic retroversion (3.7\%) belonged to the complex type of the hip-spine syndrome (according to Offierski and MacNab) and required further observation and evaluation of the results after surgery. Patients with a dominant pain in the lumbosacral spine (Spine-hip group) had compensatory retroversion of the pelvis and hypolordosis of the lumbar spine. Seven cases of a normal position of the pelvis (10.6\%) had one-segment instability of grade 1 due to initial degenerative changes (changes in the disc corresponded to Pffiraman grades 2 and 3), degenerative changes in the hip corresponded to stages 1 and 2 of unilateral coxarthrosis. The clinical picture of these patients, according to the questionnaires, is a moderate decrease in the quality of life: ODI was $40.3 \pm 9.8$, HHS was $75.4 \pm 7.3$. The normal position of the pelvis in these patients can be explained by a compensatory mechanism that has not started yet due to mild degenerative changes in the spine and hip joints. 
In our opinion, the results of this study would have is difficult, and sometimes impossible, to identify the a practical value for surgeons in the situations when it dominant pathology in the hip-spine syndrome.

\section{CONCLUSION}

Patients with hip-spine syndrome and prevailing hip pathology have normal anteversion preserved or compensatory pelvic hyperantversion with hyperlordosis of the lumbar spine while the patients with the clinical prevalence of spine-hip syndrome have the reverse mechanism, pelvic retroversion with hypolordosis of the lumbar spine. The clinical picture and the functional status of the patients of this nosological group prove a low level of quality of life and a predominantly sedentary lifestyle, characteristic of these patients.

Limitations This work requires further research with a multicenter and inter-observer assessment of the validity of the parameters studied. It is also planned to evaluate the parameters of the sagittal balance after surgical treatment in order to identify the presence or absence of the patterns obtained.

\section{REFERENCES}

1. Kavalerskii G.M., Cherepanov V.G., Korkunov A.L., Lychagin A.V., Sereda A.P. Degenerativno-distroficheskie porazheniia poiasnichno-kresttsovogo otdela pozvonochnika pri Hip-Spine sindrome: khirurgicheskoe lechenie [Degenerative-dystrophic involvements of the lumbosacral spine in Hip-Spine syndrome: surgical treatment]. Kafedra Travmatologii i Ortopedii, 2013 , no. 3 (7), pp. 4-9. (in Russian)

2. Sikilinda V.D., Alabut A.V. Problemy diagnostiki i lecheniia bolnykh s sindromom Hip-Spine [Problems of diagnosis and treatment of patients with Hip-Spine syndrome]. Glavnyi Vrach Iuga Rossii, 2015, no. 4 (46), pp. 24-26. (in Russian)

3. Prodan A.I., Khvisiuk A.N. Korreliatsiia parametrov sagittalnogo pozvonochno-tazovogo balansa i degenerativnykh izmenenii nizhnepoiasnichnykh segmentov [Correlation of the parameters of sagittal spinopelvic balance and degenerative changes in the lower-lumbar segments]. Khirurgiia Pozvonochnika, 2007, no. 1, pp. 4-51. (in Russian)

4. Vakulenko V.M. Kontseptsiia vedeniia bolnykh koksartrozom na fone degenerativno-distroficheskogo porazheniia poiasnichnokresttsovogo otdela pozvonochnika [The concept of managing patients with coxarthrosis through degenerative-dystrophic involvement of the lumbosacral spine]. Travma, 2008, vol. 9, no. 1, pp. 6-12. (in Russian)

5. Vakulenko V.M., Khudobin V.Iu., Bublik L.A. Degenerativno-distroficheskie porazheniia tazobedrennykh sustavov i pozvonochnika [Degenerative-dystrophic involvements of the hips and the spine]. Travma, 2000, vol. 1, no. 1, pp. 24-26. (in Russian)

6. Gelfenbein M.S. Mezhdunarodnyi Kongress, posviashchennyi lecheniiu khronicheskogo bolevogo sindroma posle operatsii na poiasnichnom otdele pozvonochnika "Pain management '98" (Failed back surgery syndrome) [International Congress devoted to the treatment of chronic pain syndrome after surgeries in the lumbar spine "Pain management '98" (Failed back surgery syndrome)]. Neirokhirurgiia, 2000, no. 1-2, pp. 65. (in Russian)

7. Pellisé F., Vila-Casademunt A., Ferrer M., Domingo-Sàbat M., Bagó J., Pérez-Grueso F.J., Alanay A., Mannion A.F., Acaroglu E.; European Spine Study Group, ESSG. Impact on health related quality of life of adult spinal deformity (ASD) compared with other chronic conditions. Eur. Spine J., 2015, vol. 24, no. 1, pp. 3-11. DOI: 10.1007/s00586-014-3542-1.

8. Hasegawa K., Okamoto M., Hatsushikano S., Shimoda H., Ono M., Watanabe K. Normative values of spino-pelvic sagittal alignment, balance, age, and health-related quality of life in a cohort of healthy adult subjects. Eur. Spine J., 2016, vol. 25, no. 11, pp. 3675-3686.

9. Chang K.W., Leng X., Zhao W., Ching-Wei C., Chen T.C., Chang K.I., Chen Y.Y. Quality control of reconstructed sagittal balance for sagittal imbalance. Spine, 2011, vol. 36, no. 3, pp. E186-E197. DOI: 10.1097/BRS.0b013e3181ef6828.

10.Burtsev A.V., Riabykh S.O., Kotelnikov A.O., Gubin A.V. Klinicheskie aspekty sagittalnogo balansa u vzroslykh [Clinical issues of the sagittal balance in adults]. Genij Ortopedii, 2017, vol. 23, no. 2, pp. 228-235. (in Russian)

11.Lafage V., Schwab F., Patel A., Hawkinson N., Farcy J.P. Pelvic tilt and truncal inclination: two key radiographic parameters in the setting of adults with spinal deformity. Spine, 2009, vol. 34, no. 17, pp. E599-E606. DOI: 10.1097/BRS.0b013e3181aad219.

12.Legaye J. Analysis of the dynamic sagittal balance of the lumbo-pelvi-femoral complex. In: Klika V., ed. Biomechanics in Applications. Croatia, InTech, 2011, pp. 221-246. DOI: 10.5772/19608. Available at: https://www.intechopen.com/books/ biomechanics-in-applications/analysis-of-the-dynamic-sagittal-balance-of-the-lumbo-pelvi-femoral-complex.

13.Ozer A.F., Kaner T., Bozdoğan Ç. Sagittal Balance in the Spine. Turkish Neurosurgery, 2014, vol. 24, no. Suppl. 1, pp. 13-19.

14.Shon W.Y., Sharma V., Keon O.J., Moon J.G., Suh D.H. Can pelvic tilting be ignored in total hip arthroplasty? Int. J. Surg. Case Rep., 2014, vol. 5, no. 9, pp. 633-636. DOI10.1016/j.ijscr.2014.07.015.

15.Popov I.V., Zakharin V.R., Sharov V.A., Kuzminova A.D. Analiz sagittalnogo balansa u patsientov travmatologo-ortopedicheskogo profilia [Analysis of the sagittal balance in traumatologic-orthopedic patients]. Smolenskii Meditsinskii Almanakh, 2018, no. 2, pp. 75-78. (in Russian)

16.Shapovalov V.M., Averkiyev V.A., Kudiashev A.L., Artiukh V.A., Kapilevich B.Ya. Vosstanovlenie sagittalnogo pozvonochnotazovogo balansa u bolnogo s sochetannym porazheniem tazobedrennykh sustavov i pozvonochnika (klinicheskoe nabliudenie) [Restoration of sagittal spine-pelvis balance in a patient with combined injury of the hips and the spine (A clinical study)]. Genij Ortopedii, 2011, no. 3, pp. 152-155. (in Russian)

17.Averkiev A.V., Kudiashev A.L., Artiukh V.A., Nadulich K.A., Teremshonok A.V., Nagornyi E.B. Osobennosti sagittalnykh pozvonochno-tazovykh vzaimootnoshenii u patsientov $\mathrm{s}$ koksovertebralnym sindromom [Special characteristics of sagittal spinopelvic relations in patients with coxovertebral syndrome]. Khirurgiia Pozvonochnika, 2012, no. 4, pp. 49-54. (in Russian) 
18.Kudiashev A.L., Shapovalov V.M., Averkiev V.A., Nadulich K.A., Teremshonok A.V., Rezvantsev M.V., Kuzovinskii P.A., Miroevskii F.V., Kapilevich B.Ia. Razvitie degenerativno-distroficheskikh izmenenii pozvonochnika u bolnykh s koksartrozom i narusheniem sagittalnogo pozvonochno-tazovogo balansa [Development of degenerative-dystrophic changes of the spine in patients with coxarthrosis and disordered sagittal spinopelvic balance]. Vestnik Rossiiskoi Voenno-Meditsinskoi Akademii, 2013, no. 3 (43), pp. 70-74 (in Russian)

19.Khominets V.V., Kudiashev A.L., Shapovalov V.M., Miroevskii V.F. Sovremennye podkhody k diagnostike sochetannoi degenerativno-distroficheskoi patologii tazobedrennogo sustava i pozvonochnika [Modern approaches to diagnosing the combined degenerative-dystrophic pathology of the hip and the spine]. Travmatologiia i Ortopediia Rossii, 2014, no. 4 (74), pp. 16-26. (in Russian)

20.Lazennec J.Y., Brusson A., Rousseau M.A. Hip-spine relations and sagittal balance clinical consequences. Eur. Spine J., 2011, vol. 20, no. Suppl. 5, pp. 686-698. DOI: 10.1007/s00586-011-1937-9.

21.Matsuyama Y., Hasegawa Y., Yoshihara H., Tsuji T., Sakai Y., Nakamura H., Kawakami N., Kanemura T., Yukawa Y., Ishiguro N. Hip-spine syndrome: total sagittal alignment of the spine and clinical symptoms in patients with bilateral congenital hip dislocation. Spine, 2004, vol. 29, no. 21, pp. 2432-2437.

22.Radcliff K.E., Orozco F., Molby N., Delasotta L., Chen E., Post Z., Ong A. Change in spinal alignment after total hip arthroplasty. Orthop. Surg., 2013, vol. 5, no. 4, pp. 261-265. DOI: 10.1111/os.12076.

23.Weng W.J., Wang W.J., Wu M.D., Xu Z.H., Xu L.L., Qiu Y. Characteristics of sagittal spine-pelvis-leg alignment in patients with severe hip osteoarthritis. Eur. Spine J., 2015, vol. 24, no. 6, pp. 1228-1236. DOI: 10.1007/s00586-014-3700-5.

24.Offierski C.M., MacNab I. Hip-spine syndrome. Spine, 1983, vol. 8, no. 3, pp. 316-321.

25. Yoshimoto H., Sato S., Masuda T., Kanno T., Shundo M., Hyakumachi T., Yanagibashi Y. Spinopelvic alignment in patients with osteoarthrosis of the hip: a radiographic comparison to patients with low back pain. Spine, 2005, vol. 30, no. 14, pp. $1650-1657$.

26.Mellin G. Correlations of hip mobility with degree of back pain and lumbar spinal mobility in chronic low-back pain patients. Spine, 1988, vol. 13, no. 6, pp. 668-670.

27.Itoi E. Roentgenographic analysis of posture in spinal osteoporotics. Spine, 1991, vol. 16, no. 7, pp. 750-756.

28.Nakamura Y., Funayama K., Kita J. Hip-spine syndrome: tracing of coxarthropathy and the relationship between the lumbar and sacral angles. Sendai Red. Cross. Med. J., 1996, vol. 5, pp. 73-76.

29.Giles L.G., Taylor J.R. Low-back pain associated with leg length inequality. Spine, 1981, vol. 6, no. 5, pp. 510-521. DOI: 10.1097/00007632-198109000-00014.

30.Sato K., Itoi E., Kasama F. Abnormal posture associated with osteoporosis. J. Muskuloskeletal System, 1989, vol. 2, pp. 1451-1462.

31.Vad V.B., Bhat A.L., Basrai D., Gebeh A., Aspergren D.D., Andrews J.R. Low back pain in professional golfers: the role of associated hip and low back range-of-motion deficits. Am. J. Sports Med., 2004, vol. 32, no. 2, pp. 494-497.

32.Morimoto T., Kitajima M., Tsukamoto M., Yoshihara T., Sonohata M., Mawatari M. Sagittal spino-pelvic alignment in rapidly destructive coxarthrosis. Eur. Spine J., 2018, vol. 27, no. 2, pp. 475-481. DOI: 10.1007/s00586-017-5282-5.

33.Fogel G.R., Esses S.I. Hip spine syndrome: management of coexisting radiculopathy and arthritis of the lower extremity. Spine J., 2003, vol. 3, no. 3, pp. 238-241.

34.Devin C.J., McCullough K.A., Morris B.J., Yates A.J., Kang J.D. Hip-spine syndrome. J. Am. Acad. Orthop. Surg., 2012, vol. 20, no. 7, pp. 434-442. DOI: 10.5435/JAAOS-20-07-434.

35.Shchurova E.N., Khomchenkov M.V., Kamshilov B.V., Chegurov O.K., Prudnikova O.G. Differentsialnaia diagnostika Hip-Spine sindroma na etape predoperatsionnoi podgotovki [Differential diagnostics of the Hip-Spine syndrome at the stage of preoperative preparation]. Genij Ortopedii, 2012, no. 4, pp.125-127. (in Russian)

36.Byvaltsev V.A., Stepanov I.A., Kalinin A.A., Belykh E.G. Primenenie izmeriaemogo koeffitsienta diffuzii v diagnostike degeneratsii poiasnichnykh mezhpozvonkovykh diskov u patsientov pozhilogo i starcheskogo vozrasta metodom diffuzionno-vzveshennoi MRT [Using the measured diffusion coefficient in diagnostics of lumbar interbody disk degeneration in elderly and senile patients by the method of diffusion-weighted MRI]. Uspekhi Gerontologii, 2018, vol. 31, no. 1, pp.103-109. (in Russian)

37.Byvaltsev V.A., Kalinin A.A., Okoneshnikova A.K. Analiz klinicheskoi effektivnosti primeneniia metoda fasetoplastiki pri lechenii faset-sindroma v poiasnichnom otdele pozvonochnika u patsientov pozhilogo i starcheskogo vozrasta [Analysis of clinical efficiency of facetoplasty method use in treatment of facet-syndrome in the lumbar spine in elderly and senile patients]. Uspekhi Gerontologii, 2017, vol. 30, no. 1, pp. 84-91. (in Russian)

38.Schwab F., Dubey A., Gamez L., El Fegoun A.B., Hwang K., Pagala M., Farcy J.P. Adult scoliosis: prevalence, SF-36, and nutritional parameters in an elderly volunteer population. Spine, 2005, vol. 30, no. 9, pp. 1082-1085.

39.Schwab F., Patel A., Ungar B., Farcy J.P., Lafage V. Adult spinal deformity-postoperative standing imbalance: how much can you tolerate? An overview of key parameters in assessing alignment and planning corrective surgery. Spine, 2010, vol. 35, no. 25, pp. 2224-2231. DOI: 10.1097/BRS.0b013e3181ee6bd4.

40.Lu D.C., Chou D. Flatback syndrome. Neurosurg. Clin. N. Am., 2007, vol. 18, no. 2, pp. 289-294.

41.Lafage V., Schwab F., Patel A., Hawkinson N., Farcy J.P. Pelvic tilt and truncal inclination: two key radiographic parameters in the setting of adults with spinal deformity. Spine, 2009, vol. 34, no. 17, pp. E599-E606. DOI: 10.1097/BRS.0b013e3181aad219.

42.Schwab F., Lafage V., Patel A., Farcy J.P. Sagittal plane considerations and the pelvis in the adult patient. Spine, 2009, vol. 34, no. 17, pp. 1828-1833. DOI: 10.1097/BRS.0b013e3181a13c08.

43.Schwab F.J., Patel A., Shaffrey C.I., Smith J.S., Farcy J.P., Boachie-Adjei O., Hostin R.A., Hart R.A., Akbarnia B.A., Burton D.C., Bess S., Lafage V. Sagittal realignment failures following pedicle subtraction osteotomy surgery: are we doing enough?: Clinical article. J. Neurosurg. Spine, 2012, vol. 16, no. 6, pp. 539-546. DOI: 10.3171/2012.2.SPINE11120.

44.Klineberg E., Schwab F., Smith J.S., Gupta M.C., Lafage V., Bess S. Sagittal spinal pelvic alignment. Neurosurg. Clin. N. Am., 2013, vol. 24, no. 2, pp. 157-162. DOI: 10.1016/j.nec.2012.12.003.

45.Berthonnaud E., Dimnet J., Roussouly P., Labelle H. Analysis of the sagittal balance of the spine and pelvis using shape and orientation parameters. J. Spinal Disord. Tech., 2005, vol. 18, no. 1, pp. 40-47.

46.Dubousset J. Three-dimensional analysis of the scoliotic deformity. In: Weinstein S.L., ed. The pediatric spine: principles and 
practice. New York, NY, Raven Press, 1994, pp. 479-496.

47.Ames C.P., Smith J.S., Scheer J.K., Bess S., Bederman S.S., Deviren V., Lafage V., Schwab F., Shaffrey C.I. Impact of spinopelvic alignment on decision making in deformity surgery in adults: A review. J. Neurosurg. Spine, 2012, vol. 16, no. 6, pp. 547-564. DOI: 10.3171/2012.2.SPINE11320.

48.Duval-Beaupère G., Schmidt C., Cosson P. A Barycentremetric study of the sagittal shape of spine and pelvis: the conditions required for an economic standing position. Ann. Biomed. Eng., 1992, vol. 20, no. 4, pp. 451-462.

49.Liu S., Schwab F., Smith J.S., Klineberg E., Ames C.P., Mundis G., Hostin R., Kebaish K., Deviren V., Gupta M., Boachie-Adjei O., Hart R.A., Bess S., Lafage V. Likelihood of reaching minimal clinically important difference in adult spinal deformity: a comparison of operative and nonoperative treatment. Ochsner. J., 2014, vol. 14, no. 1, pp. 67-77.

50.Vialle R., Levassor N., Rillardon L., Templier A., Skalli W., Guigui P. Radiographic analysis of the sagittal alignment and balance of the spine in asymptomatic subjects. J. Bone Joint Surg. Am., 2005, vol. 87, no. 2, pp. 260-267.

51.Kim S.B., Lee G.S., Won Y.G., Jun J.B., Hwang C.M., Hong C.H. Radiologic findings of pelvic parameters related to sagittal balance. J. Korean Soc. Spine Surg., 2016, vol. 23, no. 3, pp. 197-205. URL: https://doi.org/10.4184/jkss.2016.23.3.197.

52.Lafage V., Schwab F., Skalli W., Hawkinson N., Gagey P.M., Ondra S., Farcy J.P. Standing balance and sagittal plane spinal deformity: analysis of spinopelvic and gravity line parameters. Spine, 2008, vol. 33, no. 14, pp. 1572-1578. DOI: 10.1097/ BRS.0b013e31817886a2.

53.Ivanov D.V., Hominets V.V., Kirillova I.V., Kossovich L.Yu., Kudyashev A.L., Teremshonok A.V. Biomechanics of compensatory mechanisms in spinal-pelvic complex. Journal of Physics: Conference Series, 2018, vol. 991, conference 1, pp. 1-7.

54.Hallager D.W., Hansen L.V., Dragsted C.R., Peytz N., Gehrchen M., Dahl B. A comprehensive analysis of the SRS-Schwab Adult Spinal Deformity Classification and Confounding Variables: A Prospective, Non-US Cross-sectional Study in 292 Patients. Spine, 2016, vol. 41, no. 10, pp. E589-E597. DOI: 10.1097/BRS.0000000000001355.

55.Aoki Y., Nakajima A., Takahashi H., Sonobe M., Terajima F., Saito M., Takahashi K., Ohtori S., Watanabe A., Nakajima T., Takazawa M., Orita S., Eguchi Y., Nakagawa K. Influence of pelvic incidence-lumbar lordosis mismatch on surgical outcomes of short- segment transforaminal lumbar interbody fusion. BMC. Musculoskelet. Disord., 2015, vol. 16, pp. 213. DOI: 10.1186/ s12891-015-0676-1.

56.Mac-Thiong J.M., Roussouly P., Berthonnaud E., Guigui P. Sagittal parameters of global spinal balance: normative values from a prospective cohort of seven hundred nine Caucasian asymptomatic adults. Spine, 2010, vol. 35, no. 22, pp. E1193-E1198. DOI: 10.1097/BRS.0b013e3181e50808.

57.Rose P.S., Bridwell K.H., Lenke L.G., Cronen G.A., Mulconrey D.S., Buchowski J.M., Kim Y.J. Role of pelvic incidence, thoracic kyphosis, and patient factors on sagittal plane correction following pedicle subtraction osteotomy. Spine, 2009, vol. 34, no. 8, pp. 785-791. DOI: 10.1097/BRS.0b013e31819d0c86.

58.Shapovalov V.M., Kudiashev A.L., Rezvantsev M.V., Khominets V.V. Vzaimosviaz parametrov sagittalnykh I frontalnykh pozvonochno-tazovykh vzaimootnoshenii u bolnykh s odno- i dvukhstoronnim koksartrozom [Relationship of the parameters of sagittal and frontal spinopelvic relations in patients with uni- and bilateral coxarthrosis]. Medline.Ru. Biomeditsinskii Zhurnal, 2012, vol.13, no. 2, pp. 433-445. (in Russian) Available at: http://www.medline.ru/public/art/tom13/art35.html (access 01.05.2019).

Received: 11.06.2019

\section{Information about the authors:}

1.Alexander O. Kotelnikov, M.D., Russian Ilizarov Scientific Center for Restorative Traumatology and Orthopaedics, Kurgan, Russian Federation, Email: carpediem1992@mail.ru

2. Sergey O. Ryabykh, M.D., Ph.D., Russian Ilizarov Scientific Center for Restorative Traumatology and Orthopaedics, Kurgan, Russian Federation, Email: rso_@mail.ru

3. Alexander V. Burtsev, M.D., Ph.D.,

Russian Ilizarov Scientific Center for Restorative Traumatology and Orthopaedics, Kurgan, Russian Federation, Email: bav31rus@mail.ru 